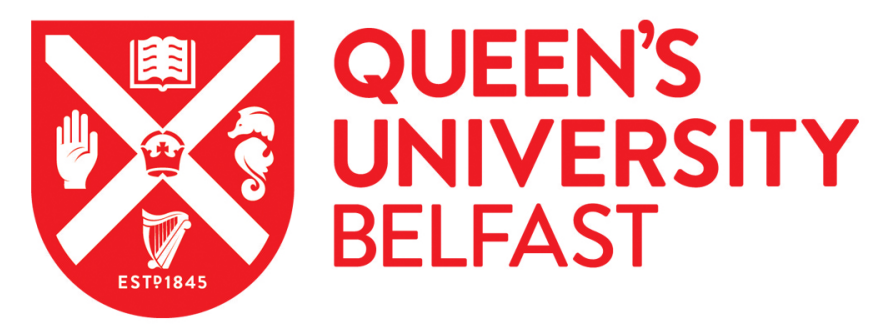

\title{
Low-pressure solubilities and thermodynamics of solvation of eight gases in 1-butyl-3-methylimidazolium hexafluorophosphate
}

Jacquemin, J., Husson, P., Majer, V., \& Gomes, M. F. C. (2006). Low-pressure solubilities and thermodynamics of solvation of eight gases in 1-butyl-3-methylimidazolium hexafluorophosphate. Fluid Phase Equilibria, 240(1), 87-95. http://www.scopus.com/inward/record.url?eid=2-s2.0-

30644470551\&partnerID=40\&md5=962406744fc7428be85d880729962a22

Published in:

Fluid Phase Equilibria

Document Version:

Early version, also known as pre-print

Queen's University Belfast - Research Portal:

Link to publication record in Queen's University Belfast Research Portal

\section{General rights}

Copyright for the publications made accessible via the Queen's University Belfast Research Portal is retained by the author(s) and / or other copyright owners and it is a condition of accessing these publications that users recognise and abide by the legal requirements associated with these rights.

Take down policy

The Research Portal is Queen's institutional repository that provides access to Queen's research output. Every effort has been made to ensure that content in the Research Portal does not infringe any person's rights, or applicable UK laws. If you discover content in the Research Portal that you believe breaches copyright or violates any law, please contact openaccess@qub.ac.uk. 


\title{
Low-pressure solubilities and thermodynamics of solvation of eight gases in 1-butyl-3-methylimidazolium hexafluorophosphate
}

\author{
Johan Jacquemin, Pascale Husson, Vladimir Majer, Margarida F. Costa Gomes* \\ Laboratoire de Thermodynamique des Solutions et des Polymères, UMR 6003 CNRS/Université Blaise Pascal, Clermont-Ferrand, \\ 24 Avenue des Landais, 63177 Aubière Cedex, France
}

Received 19 September 2005; received in revised form 30 November 2005; accepted 1 December 2005

\begin{abstract}
Experimental values for the solubility of carbon dioxide, ethane, methane, oxygen, nitrogen, hydrogen, argon and carbon monoxide in 1-butyl3-methylimidazolium hexafluorophosphate, $[\mathrm{bmim}]\left[\mathrm{PF}_{6}\right]$ - a room temperature ionic liquid - are reported as a function of temperature between 283 and $343 \mathrm{~K}$ and at pressures close to atmospheric. Carbon dioxide is the most soluble and hydrogen is the least soluble of the gases studied with mole fraction solubilities of the order of $10^{-2}$ and $10^{-4}$, respectively. All the mole fraction solubilities decrease with temperature except for hydrogen for which a maximum is observed at temperatures close to $310 \mathrm{~K}$. From the variation of solubility, expressed as Henry's law constants, with temperature, the partial molar thermodynamic functions of solvation such as the standard Gibbs energy, the enthalpy, and the entropy are calculated. The precision of the experimental data, considered as the average absolute deviation of the Henry's law constants from appropriate smoothing equations, is better than $\pm 1 \%$.
\end{abstract}

(C) 2005 Elsevier B.V. All rights reserved.

Keywords: Solubility; Gases; Ionic liquids; bmimPF $_{6}$

\section{Introduction}

In the present paper we report the solubility of different gases in one ionic liquid between 283 and $343 \mathrm{~K}$ and at pressures close to atmospheric. The knowledge of the gas solubility in this new family of liquid solvents is useful from a practical point of view as these data are valuable in the calculation of vapour/liquid equilibria for reaction systems or separation processes. From a more fundamental perspective, gas solubility measurements provide a reliable way to calculate the thermodynamic properties of solution and to assess the molecular mechanisms involved in the solvation process.

The ionic liquid chosen for this study, 1-butyl-3-methylimidazolium hexafluorophosphate, $[\mathrm{bmim}]\left[\mathrm{PF}_{6}\right]$ has already been studied by a considerable number of research groups. Some discrepancies have been observed in the literature concerning the phase equilibrium behaviour of this particular ionic liquid and some authors have even recommended that no further investiga-

\footnotetext{
* Corresponding author. Tel.: +33 473407205; fax: +33473407185 .

E-mail address: margarida.c.gomes@univ-bpclermont.fr (M.F.C. Gomes).
}

tions should be done in this ionic liquid [1] although it has in the past been considered, among imidazolium based ionic liquids, as a promising solvent for technological applications.

The solubility of gases in $\left[\mathrm{bmim}^{2}\right]\left[\mathrm{PF}_{6}\right]$ has been determined by several research groups using different techniques and Henry's law constants could be determined both from data obtained at pressures close to atmospheric $[2-6,23,24]$ or by extrapolation of values obtained at higher pressures $[1,7-12,25]$. When carbon dioxide is the studied gaseous solute, the values in the literature for the Henry's law constants are all in accord approximately to within $\pm 10 \%$ [3,4,8,7,10,24-26]. For other gases studied by different research groups, namely oxygen, carbon monoxide and hydrogen, the discrepancies found are much larger, sometimes more than $100 \%$.

In this paper, experimental solubilities of eight gases in one ionic liquid $[\mathrm{bmim}]\left[\mathrm{PF}_{6}\right]$ are reported as a function of temperature between 283 and $343 \mathrm{~K}$ near $0.1 \mathrm{MPa}$ using a high precision isochoric saturation method [14,16]. These solubility data allow the calculation of the Henry's law constants as a function of temperature and from there the thermodynamic properties of solvation. The Gibbs energy of solvation considered as the change in Gibbs energy when the solute is transferred at 
constant temperature from the pure perfect gas at $0.1 \mathrm{MPa}$ to the infinitely dilute standard state in the solvent is calculated directly from the Henry's law constants and the standard enthalpy and entropy of solvation from their variation with temperature.

\section{Experimental}

The sample of 1-butyl-3-methylimidazolium hexafluorophosphate used was purchased from Solvionic, France, with a minimum stated mole fraction purity of 0.999 . The water content of this ionic liquid, considered as hydrophobic, was carefully determined before and after the solubility measurements as this impurity seems to influence significantly its thermodynamic and thermophysical properties [13]. A Karl-Fischer volumetric titrator from Mettler Toledo (model DL31) was used and a reference value of $150 \pm 15 \mathrm{ppm}$ was found after drying the liquid for $15 \mathrm{~h}$ at $T=343 \mathrm{~K}$ under vacuum. Several tests were done to check the time and the conditions for drying and degassing the ionic liquid sample - it is considered that, in the case of [bmim] $\left[\mathrm{PF}_{6}\right]$ the liquid is appropriately degassed and dried after pumping it under a pressure of $1 \mathrm{~Pa}$ for $8 \mathrm{~h}$ at a fixed temperature between 303 and $343 \mathrm{~K}$.

The gases used have the following specifications: carbon dioxide from AGA/Linde Gaz, mole fraction purity of 0.99995 ; ethane from AGA/Linde Gaz, mole fraction purity of 0.995 ; methane from AGA/Linde Gaz, mole fraction purity of 0.99995 ; oxygen from AGA/Linde Gaz, mole fraction purity of 0.99999 ; nitrogen from SAGA, mole fraction purity 0.9998; hydrogen from AGA/Linde Gaz, mole fraction purity of 0.999997; argon from AGA/Linde Gaz, mole fraction purity of 0.999997; and carbon monoxide from AGA/Linde Gaz, mole fraction purity of 0.99997. All gases were used as received from the manufacturer.

The experimental method used for these gas solubility measurements is based on an isochoric saturation technique and has been described in previous publications [14-16]. In this technique, a known quantity of gaseous solute is put in contact with a precisely determined quantity of degassed solvent at a constant temperature inside an accurately known volume. When thermodynamic equilibrium is attained, the pressure above the liquid solution is constant and is directly related to the solubility of the gas in the liquid.

The quantity of ionic liquid introduced in the equilibration cell, $V_{\text {liq }}$, is determined gravimetrically. The amount of solute present in the liquid solution, $n_{2}^{\text {liq }}$ (subscript 2 stands for solute and subscript 1 stands for solvent), is calculated by the difference between two $p V T$ measurements: first when the gas is introduced in a calibrated bulb with volume $V_{\mathrm{GB}}$ and second after thermodynamic equilibrium is reached:

$n_{2}^{\mathrm{liq}}=\frac{p_{\mathrm{ini}} V_{\mathrm{GB}}}{\left[Z_{2}\left(p_{\mathrm{ini}}, T_{\mathrm{ini}}\right) R T_{\mathrm{ini}}\right]}-\frac{p_{\mathrm{eq}}\left(V_{\mathrm{tot}}-V_{\mathrm{liq}}\right)}{\left[Z_{2}\left(p_{\mathrm{eq}}, T_{\mathrm{eq}}\right) R T_{\mathrm{eq}}\right]}$

where $p_{\text {ini }}$ and $T_{\text {ini }}$ are the pressure and temperature in the first $p V T$ determination and $p_{\mathrm{eq}}$ and $T_{\mathrm{eq}}$ are the pressure and temperature at the equilibrium. $V_{\text {tot }}$ is the total volume of the equilibration cell and $Z_{2}$ is the compressibility factor for the pure gas. The solubility can then be expressed in mole fraction:

$x_{2}=\frac{n_{2}^{\text {liq }}}{\left(n_{1}^{\text {liq }}+n_{2}^{\text {liq }}\right)}$

or as Henry's law constant:

$K_{\mathrm{H}}=\lim _{x_{2} \rightarrow 0} \frac{f_{2}\left(p, T, x_{2}\right)}{x_{2}} \cong \frac{\phi_{2}\left(p_{\mathrm{eq}}, T_{\mathrm{eq}}\right) p_{\mathrm{eq}}}{x_{2}}$

where $f_{2}$ is the fugacity of the solute and $\phi_{2}$ its fugacity coefficient. The fugacity coefficient, which is close to unity in the present case, was included in the calculation of the Henry's law constants for all the gases. It was observed that the values do not change significantly from the ones calculated by taken $\phi_{2}=1$. It was decided however to include the fugacity coefficients in the data reduction as, in the case of carbon dioxide and ethane, the Henry's law constants changed slightly (for example, a maximum change of $0.4 \%$ in the Henry's law constant for carbon dioxide was found for the value at $283.15 \mathrm{~K}$ ).

\section{Results and discussion}

For each gaseous solute studied, multiple experimental data points were obtained in the temperature interval between 283 and $343 \mathrm{~K}$ in steps of approximately $10 \mathrm{~K}$. The experimental solubilities of carbon dioxide, ethane, methane, oxygen, nitrogen, hydrogen, argon and carbon dioxide in $[\mathrm{bmim}]\left[\mathrm{PF}_{6}\right]$ are reported in Table 1. The solubility results are given as Henry's law constants and as mole fractions of solute. These last values are calculated from the experimental data on $K_{\mathrm{H}}$ (at slightly different total pressures) assuming a partial pressure of the gaseous solute equal to $0.1 \mathrm{MPa}$. The relative atomic masses used are the ones recommended by IUPAC [17] and the values of the second virial coefficients for all the gases necessary for the calculation of the compressibility factor and the fugacity coefficient, were taken from the compilation by Dymond and Smith [18]. The density of the sample of $[\mathrm{bmim}]\left[\mathrm{PF}_{6}\right]$ used as solvent during the present measurements was determined in our laboratory with a precision better than $0.01 \%$ by means of an Anton Paar densitometer (model DMA 512 P) [19]. The density values measured are reported in Table 2 and were fitted to the function (the average absolute deviation of the fit is $0.004 \%$ ):

$\rho_{[\mathrm{bmim}]\left[\mathrm{PF}_{6}\right]}\left(\mathrm{kg} \mathrm{m}^{-3}\right)=1388.82-8406.83 \times 10^{-4}(T(\mathrm{~K}))$

To get representative values of the solubility, the raw experimental data were correlated as a function of temperature by an empirical equation of the type:

$\ln \left[K_{\mathrm{H}}(T)\left(10^{5} \mathrm{~Pa}\right)\right]=\sum_{i=0}^{n} A_{i}(T(\mathrm{~K}))^{-i}$

the coefficients $A_{i}$ obtained are listed in Table 3 together with the average absolute deviations obtained for each solute. These values can be regarded as an estimation of the precision of the experimental data which is in the present case always less than $1 \%$. 
Table 1

Experimental values of gas solubilities in $[\mathrm{bmim}]\left[\mathrm{PF}_{6}\right]$ expressed both as Henry's law constants, $K_{\mathrm{H}}$ and as mole fraction, $x_{2}$, corrected for a partial pressure of solute of $0.1 \mathrm{MPa}$

\begin{tabular}{|c|c|c|c|c|}
\hline$T(\mathrm{~K})$ & $p\left(10^{2} \mathrm{~Pa}\right)$ & $K_{\mathrm{H}}\left(10^{5} \mathrm{~Pa}\right)$ & $x_{2}\left(10^{-4}\right)$ & Dev. $(\%)$ \\
\hline \multicolumn{5}{|c|}{$\mathrm{CO}_{2}$} \\
\hline 283.15 & 686.80 & 37.83 & 262.7 & +0.2 \\
\hline 293.17 & 724.99 & 46.78 & 212.6 & +0.0 \\
\hline 303.37 & 785.20 & 57.09 & 174.3 & -0.1 \\
\hline 303.38 & 761.67 & 57.11 & 174.3 & -0.1 \\
\hline 303.38 & 384.36 & 57.37 & 173.5 & -0.5 \\
\hline 313.29 & 405.64 & 68.34 & 145.7 & -0.1 \\
\hline 313.29 & 819.99 & 68.24 & 145.9 & +0.1 \\
\hline 323.20 & 828.01 & 80.53 & 123.7 & +0.3 \\
\hline 323.28 & 425.89 & 80.42 & 123.8 & +0.6 \\
\hline 325.64 & 861.75 & 84.18 & 118.3 & -0.2 \\
\hline 333.07 & 885.97 & 94.59 & 105.4 & -0.1 \\
\hline 333.09 & 445.44 & 94.35 & 105.6 & +0.1 \\
\hline 342.99 & 917.51 & 109.6 & 90.95 & -0.2 \\
\hline 343.04 & 464.29 & 109.6 & 90.93 & -0.1 \\
\hline \multicolumn{5}{|c|}{$\mathrm{C}_{2} \mathrm{H}_{6}$} \\
\hline 283.30 & 796.84 & 199.0 & 49.81 & +0.5 \\
\hline 293.28 & 825.65 & 221.0 & 44.89 & -0.2 \\
\hline 303.36 & 775.66 & 252.8 & 39.28 & -0.4 \\
\hline 303.40 & 410.14 & 253.3 & 39.21 & -0.6 \\
\hline 303.38 & 855.20 & 252.1 & 39.38 & -0.2 \\
\hline 313.27 & 802.15 & 294.3 & 33.76 & -0.2 \\
\hline 323.21 & 828.76 & 347.3 & 28.63 & +0.8 \\
\hline 323.41 & 439.67 & 348.3 & 28.55 & +0.9 \\
\hline 333.13 & 855.48 & 422.3 & 23.56 & +0.3 \\
\hline 343.10 & 882.24 & 522.4 & 19.05 & -0.6 \\
\hline 343.12 & 469.12 & 520.1 & 19.14 & -0.1 \\
\hline \multicolumn{5}{|c|}{$\mathrm{CH}_{4}$} \\
\hline 283.31 & 789.70 & 635.7 & 15.70 & +0.4 \\
\hline 293.27 & 816.75 & 693.5 & 14.39 & -0.1 \\
\hline 303.34 & 843.98 & 747.9 & 13.35 & +1.3 \\
\hline 303.37 & 851.75 & 765.3 & 13.05 & -0.9 \\
\hline 303.40 & 456.54 & 771.4 & 12.94 & -1.7 \\
\hline 313.28 & 878.79 & 832.8 & 11.99 & +0.0 \\
\hline 323.19 & 905.83 & 913.6 & 10.93 & +0.6 \\
\hline 323.20 & 484.55 & 910.6 & 10.97 & +0.9 \\
\hline 333.10 & 932.85 & 1014 & 9.851 & +0.2 \\
\hline 343.05 & 512.64 & 1123 & 8.892 & +0.3 \\
\hline 343.08 & 960.04 & 1138 & 8.779 & -1.0 \\
\hline \multicolumn{5}{|c|}{$\mathrm{O}_{2}$} \\
\hline 283.18 & 738.78 & 937.4 & 10.66 & +0.7 \\
\hline 292.97 & 763.54 & 1024 & 9.757 & -0.1 \\
\hline 303.36 & 435.75 & 1129 & 8.854 & -1.0 \\
\hline 303.37 & 812.31 & 1129 & 8.856 & -0.9 \\
\hline 303.40 & 789.85 & 1126 & 8.879 & -0.6 \\
\hline 313.28 & 837.91 & 1211 & 8.254 & +0.7 \\
\hline 323.08 & 462.07 & 1323 & 7.556 & +0.5 \\
\hline 323.23 & 863.59 & 1315 & 7.600 & +1.2 \\
\hline 333.17 & 889.21 & 1440 & 6.942 & +0.9 \\
\hline 343.00 & 488.57 & 1610 & 6.209 & -1.5 \\
\hline 343.13 & 914.87 & 1586 & 6.302 & +0.1 \\
\hline \multicolumn{5}{|c|}{$\mathrm{N}_{2}$} \\
\hline 283.27 & 787.20 & 914.2 & 10.93 & -0.3 \\
\hline 293.33 & 814.68 & 1101 & 9.082 & +0.3 \\
\hline 303.39 & 788.28 & 1291 & 7.746 & +0.5 \\
\hline 303.41 & 421.79 & 1298 & 7.701 & -0.1 \\
\hline 308.33 & 855.33 & 1393 & 7.180 & -0.1 \\
\hline 313.26 & 434.67 & 1481 & 6.750 & +0.0 \\
\hline 313.27 & 813.18 & 1482 & 6.745 & -0.0 \\
\hline 323.22 & 447.53 & 1658 & 6.031 & +0.0 \\
\hline
\end{tabular}

Table 1 (Continued)

\begin{tabular}{|c|c|c|c|c|}
\hline$T(\mathrm{~K})$ & $p\left(10^{2} \mathrm{~Pa}\right)$ & $K_{\mathrm{H}}\left(10^{5} \mathrm{~Pa}\right)$ & $x_{2}\left(10^{-4}\right)$ & Dev. $(\%)$ \\
\hline 323.24 & 838.16 & 1663 & 6.012 & -0.3 \\
\hline 333.19 & 460.31 & 1824 & 5.483 & -0.1 \\
\hline 333.20 & 863.01 & 1828 & 5.472 & -0.3 \\
\hline 343.12 & 472.90 & 1963 & 5.094 & +0.3 \\
\hline 343.15 & 887.72 & 1967 & 5.083 & +0.1 \\
\hline \multicolumn{5}{|c|}{$\mathrm{H}_{2}$} \\
\hline 283.40 & 764.43 & 3572 & 2.801 & -0.2 \\
\hline 293.40 & 789.78 & 2445 & 4.092 & +0.1 \\
\hline 303.39 & 450.46 & 1988 & 5.033 & +0.2 \\
\hline 303.39 & 815.13 & 1987 & 5.036 & +0.2 \\
\hline 303.40 & 835.71 & 1994 & 5.017 & -0.2 \\
\hline 308.17 & 827.27 & 1892 & 5.289 & +0.4 \\
\hline 313.28 & 840.34 & 1880 & 5.321 & -0.9 \\
\hline 313.29 & 861.54 & 1858 & 3.384 & +0.3 \\
\hline 313.79 & 464.29 & 1857 & 5.389 & +0.4 \\
\hline 318.16 & 852.84 & 1878 & 5.328 & +0.3 \\
\hline 323.17 & 887.60 & 1964 & 5.094 & -0.5 \\
\hline 323.23 & 477.14 & 1959 & 5.108 & -0.2 \\
\hline 333.19 & 914.15 & 2259 & 4.430 & -0.1 \\
\hline 343.12 & 940.59 & 2817 & 3.552 & +0.0 \\
\hline 343.14 & 917.32 & 2810 & 3.561 & +0.3 \\
\hline \multicolumn{5}{|c|}{$\mathrm{Ar}$} \\
\hline 283.40 & 793.49 & 860.7 & 11.61 & +0.7 \\
\hline 293.39 & 820.76 & 963.2 & 10.37 & -1.0 \\
\hline 303.41 & 840.18 & 1048 & 9.538 & -0.3 \\
\hline 303.43 & 451.79 & 1046 & 9.554 & -0.1 \\
\hline 313.32 & 866.73 & 1136 & 8.795 & +0.2 \\
\hline 313.32 & 465.56 & 1133 & 8.824 & +0.5 \\
\hline 323.28 & 893.36 & 1234 & 8.099 & +0.1 \\
\hline 333.17 & 919.72 & 1339 & 7.467 & -0.3 \\
\hline 333.21 & 493.01 & 1322 & 7.563 & +1.0 \\
\hline 343.11 & 946.16 & 1454 & 6.877 & -1.2 \\
\hline 343.15 & 506.63 & 1429 & 6.997 & +0.6 \\
\hline \multicolumn{5}{|c|}{$\mathrm{CO}$} \\
\hline 283.16 & 824.41 & 1201 & 8.320 & +0.5 \\
\hline 293.20 & 852.49 & 1236 & 8.088 & -1.0 \\
\hline 303.38 & 880.82 & 1242 & 8.051 & +0.2 \\
\hline 303.41 & 805.59 & 1241 & 8.054 & +0.2 \\
\hline 313.33 & 805.59 & 1266 & 7.896 & +0.1 \\
\hline 323.25 & 855.99 & 1292 & 7.741 & +0.2 \\
\hline 333.57 & 882.12 & 1327 & 7.536 & -0.2 \\
\hline 343.27 & 906.62 & 1356 & 7.372 & -0.1 \\
\hline
\end{tabular}

$p$ is the experimental equilibrium pressure and the per cent deviation is relative to the correlations of the data reported in Table 2 .

In Fig. 1 are represented the solubility data expressed in mole fraction, for the gases in the ionic liquid as a function of temperature. As it can be observed in the upper plot, carbon dioxide is the most soluble of the gases studied followed by ethane and the six other gaseous solutes. In the lower plot of Fig. 1 are represented the data for the less soluble gases. Of the six less soluble gases, methane is the most soluble. Oxygen and argon exhibit similar solubilities (argon is nevertheless slightly more soluble in the whole temperature range) and their variation with temperature is identical as can be seen by the parallel curves in Fig. 1. The solubility of carbon monoxide is practically constant with temperature in the range studied. Nitrogen and hydrogen show more complex variations of the solubility with the later gas exhibiting a maximum of its solubility near $313 \mathrm{~K}$. 
Table 2

Experimental values of the density $[\mathrm{bmim}]\left[\mathrm{PF}_{6}\right]$ between 283 and $343 \mathrm{~K}$

\begin{tabular}{lll}
\hline$T(\mathrm{~K})$ & $\rho\left(\mathrm{kg} \mathrm{m}^{-3}\right)$ & Dev. $(\%)$ \\
\hline 283.13 & 1380.43 & +0.000 \\
293.12 & 1372.15 & -0.008 \\
293.30 & 1371.88 & +0.000 \\
302.83 & 1363.87 & +0.000 \\
303.30 & 1363.48 & +0.000 \\
312.68 & 1355.45 & +0.010 \\
313.17 & 1355.18 & +0.000 \\
322.64 & 1347.23 & -0.001 \\
323.23 & 1346.72 & -0.000 \\
332.56 & 1338.70 & +0.013 \\
333.66 & 1337.95 & +0.000 \\
342.41 & 1330.79 & -0.015 \\
343.27 & 1329.87 & +0.000 \\
\hline
\end{tabular}

The per cent deviations are relative to the fit of Eq. (4).

Because the solubility of several gases in this ionic liquid has been studied by other research groups often as a function of temperature, it is possible to compare the results obtained in the present work with those of other authors. This comparison can constitute a guidance to estimate the accuracy of the data in this work. As it is the solubility of carbon dioxide in [bmim] $\left[\mathrm{PF}_{6}\right]$ that was determined by the largest number of research groups using different ionic liquid samples and distinct experimental techniques, we have represented in Fig. 2 a deviation plot showing differences between the various literature sources and the correlation of the present data. As it can be observed, only two data points, reported in Ref. [26], exhibit a difference of more than $10 \%$ from the present data, the majority of the literature values deviating less than $\pm 5 \%$. This last value is therefore probably a good estimate for the accuracy of the measurements described in this paper.

The solubility in $\left[\mathrm{bmim}^{\mathrm{b}}\right]\left[\mathrm{PF}_{6}\right]$ of some of the gases studied in this work was also determined by other authors. Two research groups have studied the solubility of oxygen in the ionic liquid [bmim] $\left[\mathrm{PF}_{6}\right]$. Kumelan et al. [20] have reported Henry's law constants between 293 and $373 \mathrm{~K}$ which do not exhibit a significant variation with temperature. By comparing their values with the ones reported here, important deviations are observed at the lower temperature end (up to $+75 \%$ ) which are considerably reduced at $353 \mathrm{~K}$ where a difference of mere $+3 \%$ from the correlation of our data is found. Anthony et al. [12] also report solubility data for oxygen in $\left[\mathrm{bmim}^{\mathrm{b}}\right]\left[\mathrm{PF}_{6}\right]$ at two temper-

Table 3

Parameters of Eq. (5) used to smooth the experimental results on $K_{\mathrm{H}}$ from Table 1 along with the per cent average absolute deviation of the fit (AAD)

\begin{tabular}{lclll}
\hline Gas & $A_{0}$ & $A_{1}$ & $A_{2}$ & AAD (\%) \\
\hline $\mathrm{CO}_{2}$ & +9.245 & $-1.428 \times 10^{3}$ & $-4.547 \times 10^{4}$ & 0.2 \\
$\mathrm{C}_{2} \mathrm{H}_{6}$ & +26.04 & $-1.115 \times 10^{4}$ & $+1.484 \times 10^{6}$ & 0.4 \\
$\mathrm{CH}_{4}$ & +14.80 & $-4.103 \times 10^{3}$ & $+4.933 \times 10^{5}$ & 0.7 \\
$\mathrm{O}_{2}$ & +13.19 & $-2.947 \times 10^{3}$ & $+3.265 \times 10^{5}$ & 0.7 \\
$\mathrm{~N}_{2}$ & +4.331 & $+3.071 \times 10^{3}$ & $-6.706 \times 10^{5}$ & 0.2 \\
$\mathrm{H}_{2}$ & +64.03 & $-3.546 \times 10^{4}$ & $+5.563 \times 10^{6}$ & 0.3 \\
$\mathrm{Ar}$ & +10.17 & $-1.139 \times 10^{3}$ & $+4.913 \times 10^{4}$ & 0.5 \\
$\mathrm{CO}$ & +9.343 & $-1.180 \times 10^{3}$ & $+1.539 \times 10^{5}$ & 0.3 \\
\hline
\end{tabular}
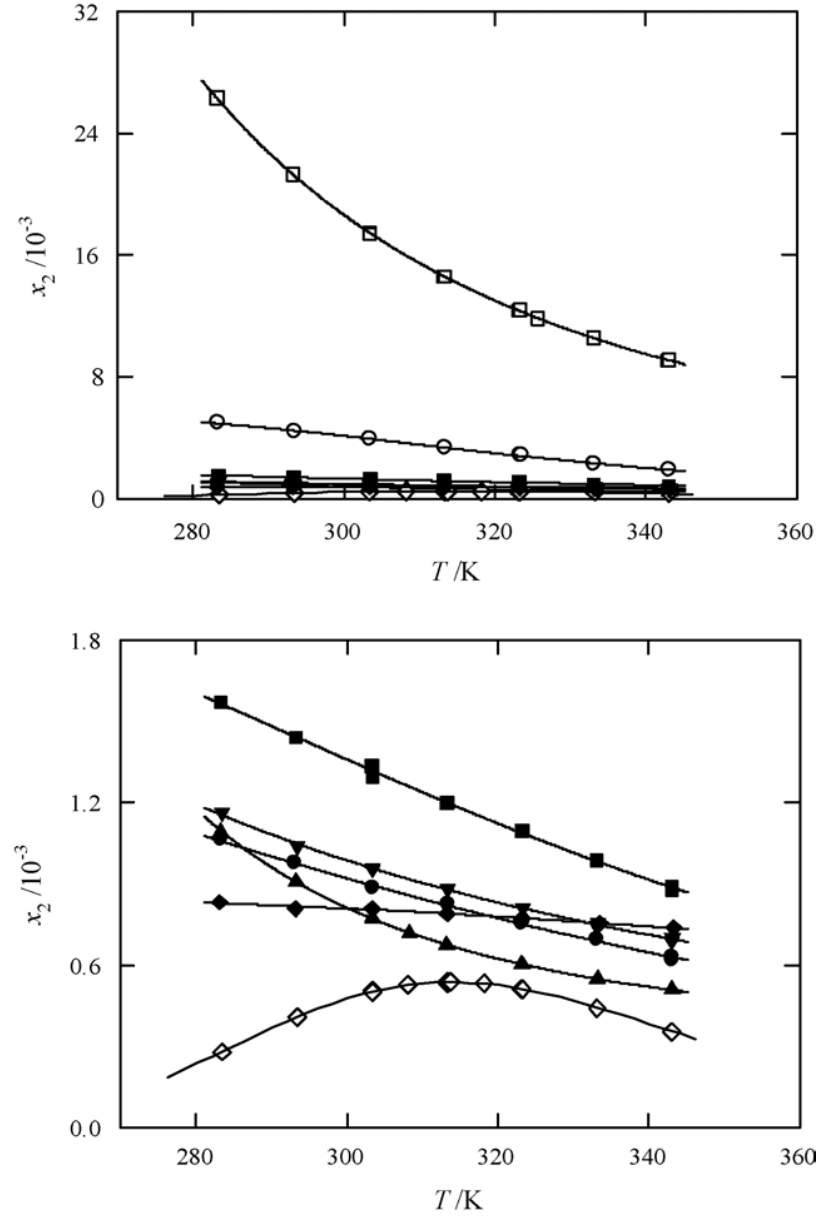

Fig. 1. Mole fraction gas solubilities in $\left[\mathrm{bmim}^{\mathrm{b}}\right]\left[\mathrm{PF}_{6}\right]$ at $0.1 \mathrm{MPa}$ partial pressure of the solute and as a function of temperature: $\square$, carbon dioxide; $\bigcirc$, ethane; $\square$ methane; $\boldsymbol{\bullet}$, oxygen; $\boldsymbol{\Lambda}$, nitrogen; $\diamond$, hydrogen; $\boldsymbol{\nabla}$, argon; $\diamond$, carbon monoxide Lines represent the smoothed data using the parameters in Table 2. In the lower plot are represented the data for the six less soluble gases in an expanded scale.

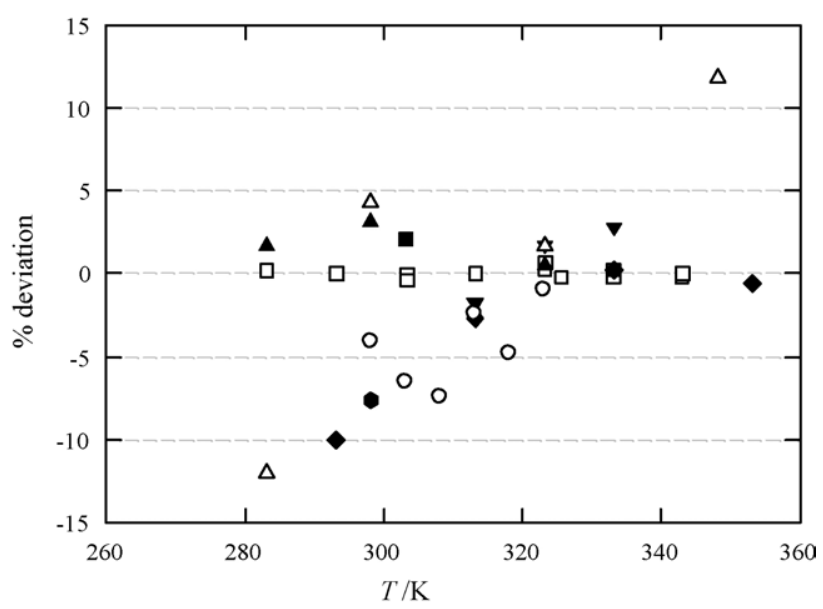

Fig. 2. Deviations from the literature values to the correlation of the Henry's law constants obtained in this work for carbon dioxide in $[\mathrm{bmim}]\left[\mathrm{PF}_{6}\right]: \square$, this work, $\mathbf{\nabla}$, Liu et al. (2003) [8]; $\diamond$, Kamps et al. (2003) [7]; $\mathbf{\square}$, Camper et al. (2004) [24]; $\boldsymbol{\Lambda}$, Cadena et al. (2004) [4] and Anthony et al. (2005) [12]; , Kim et al. (2005) [10]; ○, Zhang et al. (2005) [25]; $\triangle$, Shiflett and Yokozeki (2005) [26]. 
atures, 298 and $323 \mathrm{~K}$. In this case, a large difference from our data is observed at the lower temperature. It seems as though their value for the Henry's law constant at $298 \mathrm{~K}$ [12] is too high compared to their value at $323 \mathrm{~K}$ (almost six times larger) this last one only deviating $10 \%$ from the present data. The same picture is observed for the solubility of argon measured by the same authors that report a far too high value for the Henry's law constant at $298 \mathrm{~K}$ (circa six times larger than that at $323 \mathrm{~K}$ ). The value for the argon solubility at the higher temperature listed in Ref. [12] is only 5\% lower than that reported in the present work.

Three different research groups have tried to measure the solubility of carbon monoxide in $[\mathrm{bmim}]\left[\mathrm{PF}_{6}\right]$. Anthony et al. [12] were not able to detect it and Ohlin et al. [6] have reported a value for the Henry's law constant which is too high when compared with the data measured in this work (almost three times higher). Kumelan et al. [11] reported values for the Henry's law constant of carbon monoxide in $[\mathrm{bmim}]\left[\mathrm{PF}_{6}\right]$ from 293.2 to $373.15 \mathrm{~K}$ which lay systematically above the ones measured here (corresponding to lower mole fraction solubilities). The deviations decrease with temperature but are significant and vary from $+59 \%$ at $293.2 \mathrm{~K}$ to $+35 \%$ at $373.15 \mathrm{~K}$ (this comparison was possible by extrapolating our data using the correlation in Table 2).

Berger et al. [2] and Dyson et al. [9] have measured the solubility of hydrogen in several ionic liquids among which the one studied in the present paper. The values reported by the two research groups are different by approximately $23 \%$ and both correspond to values for the solubility of hydrogen, which are too low when compared with the data obtained in the present work.

Anthony et al. [12] also reported the solubility of ethane in the ionic liquid studied here at three temperatures between 283 and $363 \mathrm{~K}$. The Henry's law constants are higher than the ones reported in this work corresponding to lower measured gas solubilities. The deviations are significant at $298 \mathrm{~K}$ (the values in reference [12] are $43 \%$ higher than the present ones) but far less important at both temperature ends (differences of only $+16 \%$ at $283 \mathrm{~K}$ and $+3 \%$ at $323 \mathrm{~K}$ ).

The differences in the data reported by the different authors can be attributed to two major reasons. One reveals of the difficulties involved in the measurement of such low gas solubilities (typically of the order of $10^{-4}$ in mole fraction) using common experimental techniques. This statement is confirmed by observing the large error bars of some of the values obtained by other authors: for example Anthony et al. [12] reported an uncertainty of $\pm 58 \%$ for the solubility of oxygen in $\left[\mathrm{bmim}^{2}\left[\mathrm{PF}_{6}\right]\right.$ at $298 \mathrm{~K}$. Another plausible reason for the discrepancies found for the less soluble gases are impurities and degradation products very probably present in the samples of ionic liquids used by the different research groups [1].

The variation with temperature of the solubility for the eight gases studied, expressed in Henry's law constant, is directly related to the thermodynamic properties of solvation which, in the case of gaseous solutes at low pressures, is practically identical to the thermodynamic properties of solution [21]. The Gibbs energy of solvation, corresponding to the change in Gibbs energy

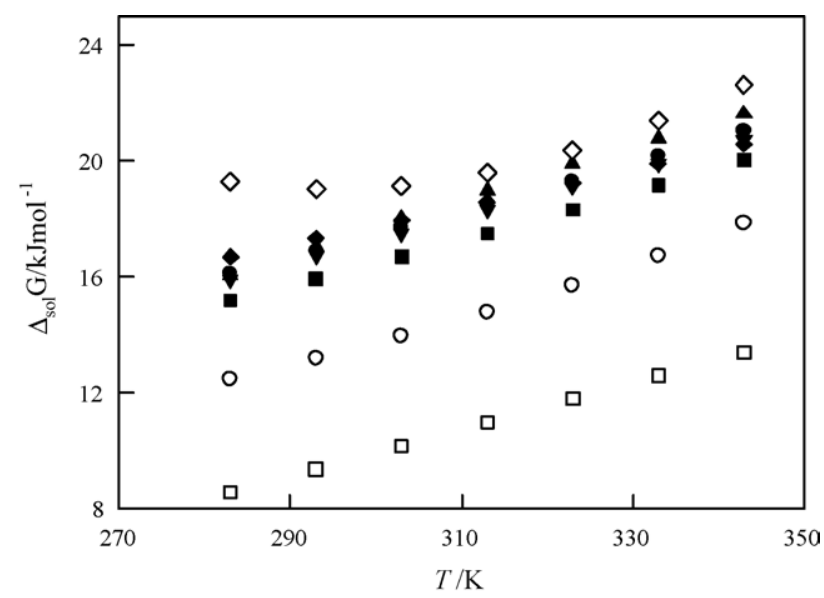

Fig. 3. Gibbs energy of solvation of the gases in $[\mathrm{bmim}]\left[\mathrm{PF}_{6}\right]$ as a function of temperature: $\square$, carbon dioxide; $\bigcirc$, ethane; $\mathbf{\square}$, methane; $\boldsymbol{\odot}$, oxygen; $\boldsymbol{\Lambda}$, nitrogen; $\diamond$, hydrogen; $\nabla$, argon; $\diamond$, carbon monoxide.

when the solute is transferred, at constant temperature, from the pure perfect gas state at the standard pressure to the standard state of infinite dilution of the solute in the solvent and is given by

$\Delta_{\mathrm{sol}} G^{\infty}=R T \ln \left(\frac{K_{\mathrm{H}}}{p^{0}}\right)$

where $p^{0}$ is the standard state pressure. The partial molar differences in enthalpy and entropy between the two states can be obtained by calculating the corresponding partial derivatives of the Gibbs energy with respect to temperature.

$\Delta_{\mathrm{sol}} H^{\infty}=-T^{2} \frac{\partial}{\partial T}\left(\frac{\Delta_{\mathrm{sol}} G^{\infty}}{T}\right)=-R T^{2} \frac{\partial}{\partial T}\left[\ln \left(\frac{K_{\mathrm{H}}}{p^{0}}\right)\right]$

$\begin{aligned} \Delta_{\mathrm{sol}} S^{\infty} & =\frac{\left(\Delta_{\mathrm{sol}} H^{\infty}-\Delta_{\mathrm{sol}} G^{\infty}\right)}{T} \\ & =-R T \frac{\partial}{\partial T}\left[\ln \left(\frac{K_{\mathrm{H}}}{p^{0}}\right)\right]-R \ln \left(\frac{K_{\mathrm{H}}}{p^{0}}\right)\end{aligned}$

The values for the Gibbs energy, enthalpy and entropy of solvation are given in Table 4 for the eight gases in $\left[\mathrm{bmim}^{\mathrm{b}}\right]\left[\mathrm{PF}_{6}\right]$ at seven discrete temperatures between 283 and $343 \mathrm{~K}$.

As it can be observed in Fig. 3, the Gibbs energy of solvation behaves with temperature in a similar manner for all the gases studied except for hydrogen for which it exhibits a minimum at temperatures close to $310 \mathrm{~K}$. The variation with temperature of the enthalpy and entropy of solution is depicted in Fig. 4. Except for the case of hydrogen, all the gases have negative enthalpies of solvation corresponding to an exothermic solvation. At the lower temperature end, carbon dioxide exhibits the most negative enthalpy of solvation; at the higher temperatures, however, ethane and hydrogen are the gases which show the most negative enthalpies of solvation. These two gases are also the only ones for which the variation of the enthalpy of solvation with temperature is more significant, especially in the case of hydrogen which presents an enthalpy of solvation positive at $283 \mathrm{~K}$, that passes through zero around $315 \mathrm{~K}$ and that then decreases 
to negative values. Carbon monoxide is the gas that dissolves in the ionic liquid with the enthalpy of solvation closest to zero, the entropy of solvation being similar to that of other gases like oxygen, argon, methane or carbon dioxide.

For the entropy of solvation, all the values are negative and lay between -70 and $-110 \mathrm{~J} \mathrm{~mol}^{-1} \mathrm{~K}^{-1}$. The exception is again hydrogen for which the values are positive at the lower temper-
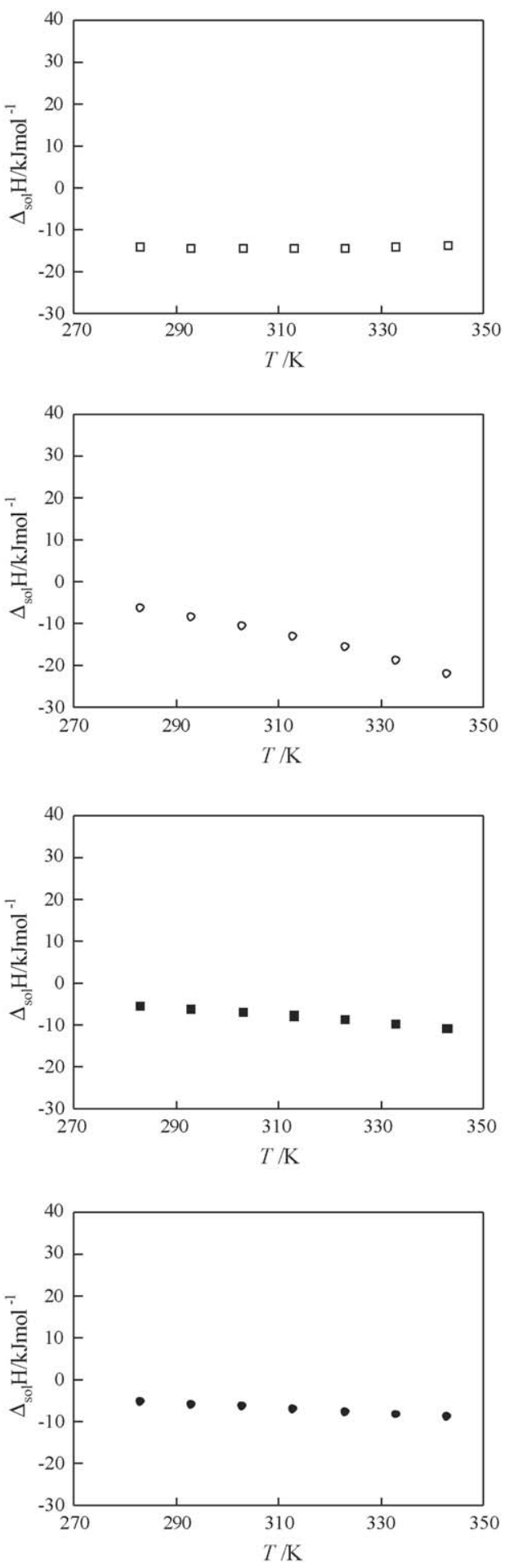

atures and then strongly decrease being the most negative found in this work at the higher temperature end. For all the other gases, the variation of the entropy of solvation with temperature is not significant: it slightly decreases with temperature in all the cases (the variation is somewhat more pronounced for ethane) with the exception of nitrogen where it slightly increases.
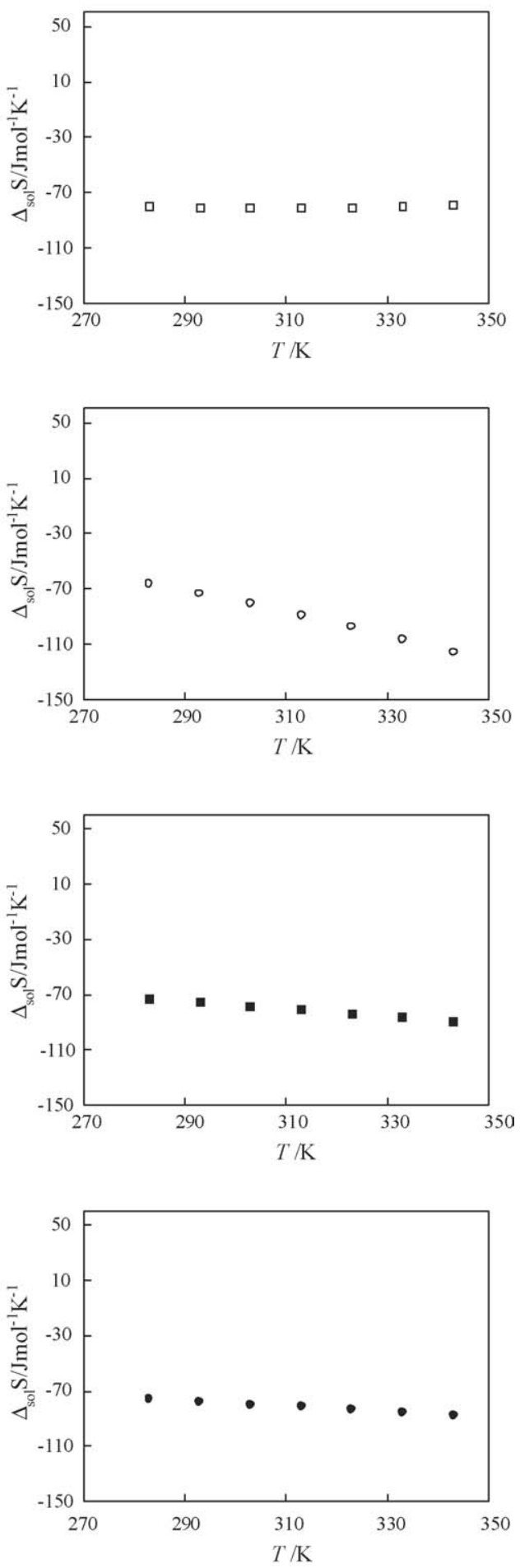

Fig. 4. Enthalpy of solvation (left) and entropy of solvation (right) of the gases in [bmim] $\left[\mathrm{PF}_{6}\right]$ as a function of temperature: $\square$, carbon dioxide; $\bigcirc$, ethane; methane; $\bullet$, oxygen; $\boldsymbol{\Lambda}$, nitrogen; $\diamond$, hydrogen; $\mathbf{\nabla}$, argon; $\downarrow$, carbon monoxide. 

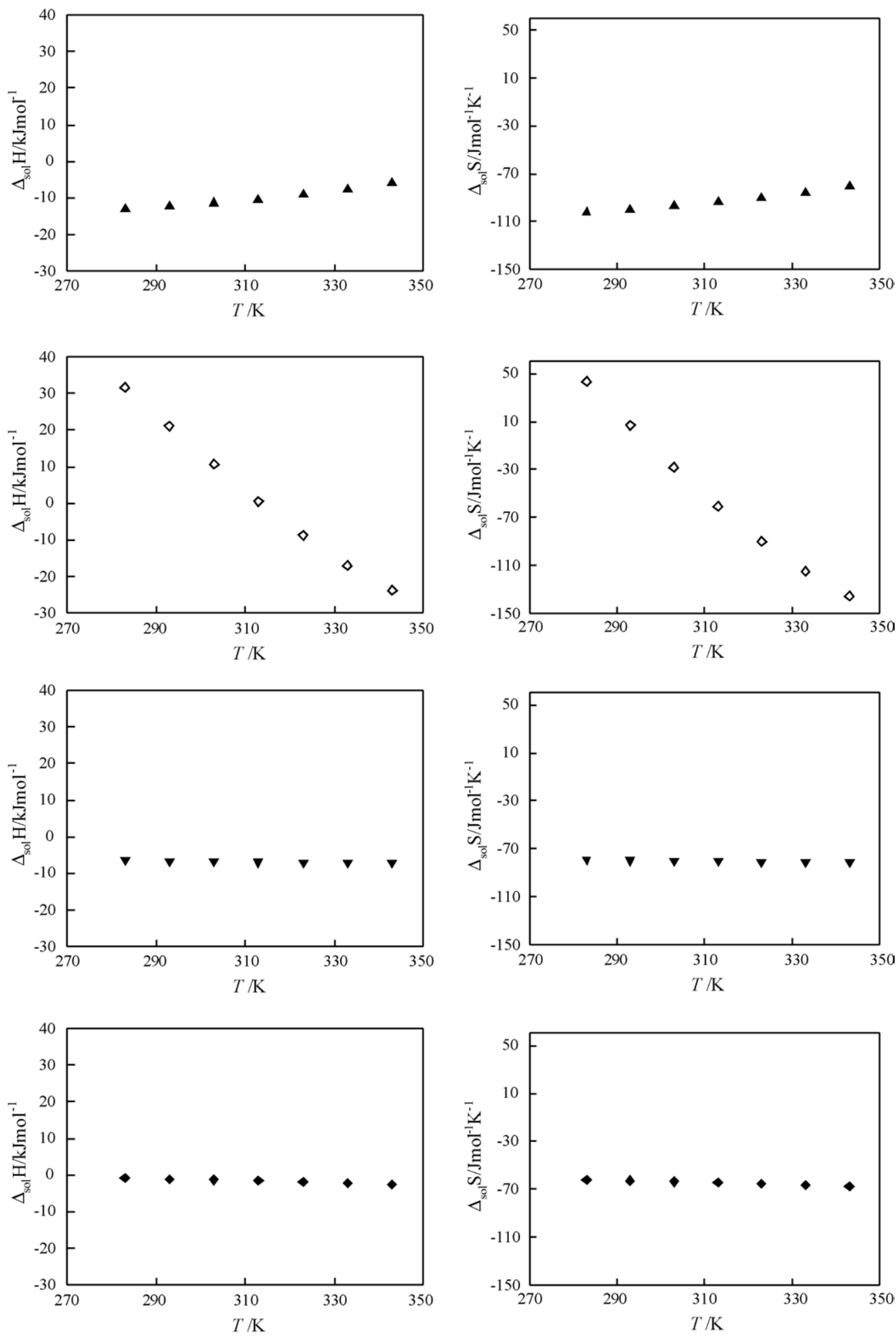

Fig. 4. (Continued).

Because the solubility data obtained are sufficiently precise, the thermodynamic properties of solvation can be used to infer about the molecular mechanisms pertaining to the solvation of the different gases in $[\mathrm{bmim}]\left[\mathrm{PF}_{6}\right]$. These properties provide valuable information both about the solute-solvent interactions and about the molecular structure of the solutions: the enthalpy of solution is closely related with the crossed gas-ionic liquid molecular interactions and the entropy of solvation gives indications about the structure of the solvent molecules surrounding the solute. The behaviour observed for the enthalpy of solution probably means that the solvent-solute interactions are of different nature in hydrogen and in the other gases studied. The same 
Table 4

Thermodynamic functions of solvation for the gases in $[\mathrm{bmim}]\left[\mathrm{PF}_{6}\right]$ at several discrete temperatures between 283 and $343 \mathrm{~K}$

\begin{tabular}{|c|c|c|c|}
\hline$T(\mathrm{~K})$ & $\Delta_{\mathrm{sol}} G^{\infty}\left(\mathrm{kJ} \mathrm{mol}^{-1}\right)$ & $\Delta_{\mathrm{sol}} H^{\infty}\left(\mathrm{kJ} \mathrm{mol}^{-1}\right)$ & $\begin{array}{l}\Delta_{\mathrm{sol}} S^{\infty} \\
\left(\mathrm{J} \mathrm{mol}^{-1} \mathrm{~K}^{-1}\right)\end{array}$ \\
\hline \multicolumn{4}{|c|}{$\mathrm{CO}_{2}$} \\
\hline 283 & 8.551 & -14.2 & -80.3 \\
\hline 293 & 9.357 & -14.3 & -80.9 \\
\hline 303 & 10.17 & -14.4 & -81.1 \\
\hline 313 & 10.98 & -14.4 & -81.1 \\
\hline 323 & 11.79 & -14.3 & -80.7 \\
\hline 333 & 12.59 & -14.1 & -80.1 \\
\hline 343 & 13.39 & -13.7 & -79.1 \\
\hline \multicolumn{4}{|c|}{$\mathrm{C}_{2} \mathrm{H}_{6}$} \\
\hline 283 & 12.45 & -6.50 & -67.0 \\
\hline 293 & 13.15 & -8.47 & -73.8 \\
\hline 303 & 13.92 & -10.7 & -81.2 \\
\hline 313 & 14.77 & -13.1 & -89.0 \\
\hline 323 & 15.71 & -15.8 & -97.5 \\
\hline 333 & 16.72 & -18.7 & -106 \\
\hline 343 & 17.84 & -21.9 & -116 \\
\hline \multicolumn{4}{|c|}{$\mathrm{CH}_{4}$} \\
\hline 283 & 15.19 & -5.46 & -73.0 \\
\hline 293 & 15.93 & -6.17 & -75.4 \\
\hline 303 & 16.70 & -6.94 & -78.0 \\
\hline 313 & 17.49 & -7.77 & -80.7 \\
\hline 323 & 18.31 & -8.67 & -83.5 \\
\hline 333 & 19.16 & -9.62 & -86.4 \\
\hline 343 & 20.04 & -10.6 & -89.5 \\
\hline \multicolumn{4}{|c|}{$\mathrm{O}_{2}$} \\
\hline 283 & 16.12 & -5.44 & -76.2 \\
\hline 293 & 16.89 & -5.96 & -78.0 \\
\hline 303 & 17.68 & -6.50 & -79.8 \\
\hline 313 & 18.48 & -7.08 & -81.7 \\
\hline 323 & 19.31 & -7.69 & -83.6 \\
\hline 333 & 20.16 & -8.33 & -85.5 \\
\hline 343 & 21.02 & -9.00 & -87.5 \\
\hline \multicolumn{4}{|c|}{$\mathrm{N}_{2}$} \\
\hline 283 & 16.03 & -12.9 & -102 \\
\hline 293 & 17.05 & -12.3 & -100 \\
\hline 303 & 18.04 & -11.5 & -97.3 \\
\hline 313 & 18.99 & -10.4 & -93.9 \\
\hline 323 & 19.91 & -9.16 & -90.0 \\
\hline 333 & 20.79 & -7.69 & -85.5 \\
\hline 343 & 21.62 & -5.99 & -80.5 \\
\hline \multicolumn{4}{|c|}{$\mathrm{H}_{2}$} \\
\hline 283 & 19.29 & +31.6 & +43.6 \\
\hline 293 & 19.04 & +21.1 & +6.89 \\
\hline 303 & 19.15 & +10.6 & -28.1 \\
\hline 313 & 19.60 & +0.60 & -60.7 \\
\hline 323 & 20.35 & -8.71 & -90.0 \\
\hline 333 & 21.38 & -17.0 & -115 \\
\hline 343 & 22.64 & -23.9 & -136 \\
\hline \multicolumn{4}{|c|}{$\mathrm{Ar}$} \\
\hline 283 & 15.91 & -6.47 & -79.1 \\
\hline 293 & 16.70 & -6.64 & -79.7 \\
\hline 303 & 17.50 & -6.78 & -80.1 \\
\hline 313 & 18.31 & -6.89 & -80.5 \\
\hline 323 & 19.11 & -6.98 & -80.8 \\
\hline 333 & 19.92 & -7.04 & -81.0 \\
\hline 343 & 20.73 & -7.06 & -81.0 \\
\hline \multicolumn{4}{|c|}{$\mathrm{CO}$} \\
\hline 283 & 16.70 & -0.87 & -62.1 \\
\hline
\end{tabular}

Table 4 (Continued)

\begin{tabular}{llll}
\hline$T(\mathrm{~K})$ & $\Delta_{\mathrm{sol}} G^{\infty}\left(\mathrm{kJ} \mathrm{mol}^{-1}\right)$ & $\Delta_{\mathrm{sol}} H^{\infty}\left(\mathrm{kJ} \mathrm{mol}^{-1}\right)$ & $\begin{array}{l}\Delta_{\mathrm{sol}} S^{\infty} \\
\left(\mathrm{J} \mathrm{mol}^{-1} \mathrm{~K}^{-1}\right)\end{array}$ \\
\hline 293 & 17.32 & -1.08 & -62.8 \\
303 & 17.95 & -1.32 & -63.6 \\
313 & 18.59 & -1.59 & -64.5 \\
323 & 19.24 & -1.87 & -65.4 \\
333 & 19.90 & -2.19 & -66.3 \\
343 & 20.57 & -2.53 & -67.3 \\
\hline
\end{tabular}

$\Delta_{\text {sol }} G^{\infty}$ is the Gibbs energy of solvation, $\Delta_{\text {sol }} H^{\infty}$ the enthalpy of solvation and $\Delta_{\text {sol }} S^{\infty}$ is the entropy of solvation. The values are consistent with $p^{0}=0.1 \mathrm{MPa}$.

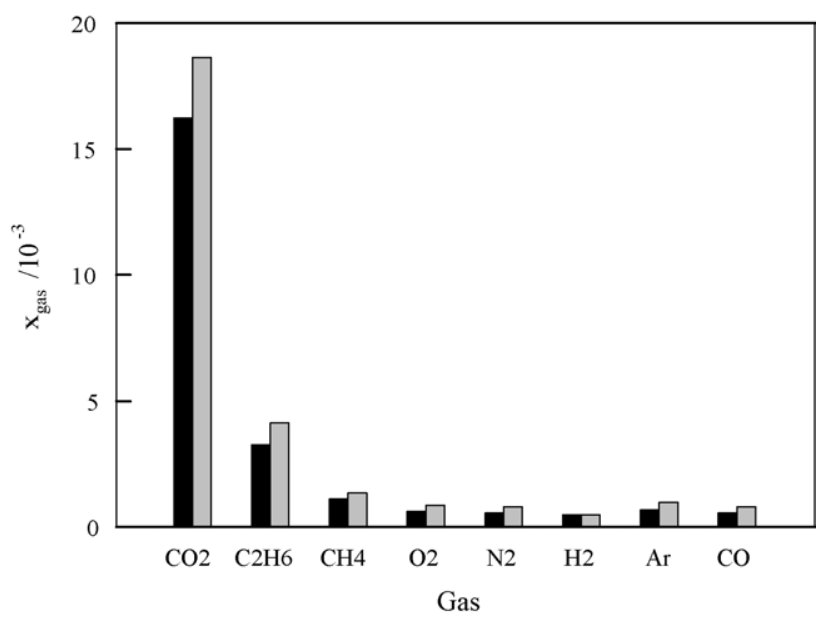

Fig. 5. Mole fraction solubility of gases in [bmim][BF4] (dark bars, reference [16]) and in $[\mathrm{bmim}]\left[\mathrm{PF}_{6}\right]$ (grey bars, this work) at a $0.1 \mathrm{MPa}$ partial pressure of the solute and at $300 \mathrm{~K}$.

is observed in the case of the entropy of solvation for which the behaviour is different in the case of hydrogen.

The present results can be confronted with a similar study recently published [16] for a similar ionic liquid (having the same cation), the 1-butyl-3-methylimidazolium tetrafluoroborate [bmim][BF4]. All the gases studied are more soluble in [bmim] $\left[\mathrm{PF}_{6}\right]$ than in $[\mathrm{bmim}][\mathrm{BF} 4]$ as can be seen in Fig. 5 for the solubility of the eight gases studied and at a chosen temperature of $300 \mathrm{~K}$ (in the case of hydrogen its solubility in the two ionic liquids is similar at this temperature). This behaviour has been predicted by computer simulation studies, also performed by our research group [22], although some experimental studies pointed out to similar solubilities in both ionic liquids [3,7]. Furthermore, a spectroscopic study for carbon dioxide in these two ionic liquids [23] also confirms the results in Fig. 5. Although stronger gas-solvent interactions were found for tetrafluoroborate (probably due to the smaller size of the anion), the more important free-volume contribution encountered in the case of hexafluorophosphate would be responsible for the larger solubilities of the gas in $[\mathrm{bmim}]\left[\mathrm{PF}_{6}\right]$.

\section{Conclusions}

We report the solubility of eight different gases in one ionic liquid: 1-butyl-3-methylimidazolium hexafluorophosphate as a function of temperature. The results could be compared with 
values published in the literature by different research groups for the case of carbon dioxide (eight different sets of data) but also for oxygen, argon, carbon monoxide, hydrogen and ethane. The analysis of the carbon dioxide solubility data allows the estimation of a realistic value for the accuracy of the present values that was established at $\pm 5 \%$. For the case of the other gaseous solutes studied, which are significantly less soluble, it is difficult to estimate the accuracy of the data. Based on a careful analysis of the sources and order of magnitude of the errors associated with our experimental technique, we are tempted to affirm that the accuracy of all the values presented in this paper is similar. However, if uncontrolled and undetected impurities or degradation products are present, these should affect more significantly the data collected for the less soluble gases.

The data obtained here makes it possible to calculate and analyse the thermodynamic properties of solvation, which can provide tools to assess the molecular interactions in solution. It was observed that, except for the case of hydrogen as a solute and to a lesser extent of ethane, the enthalpy and entropy of solution do not vary significantly for the gases studied in $[\mathrm{bmim}]\left[\mathrm{PF}_{6}\right]$ which probably points out to similar molecular mechanisms of solvation.

\section{List of symbols}

$f_{i} \quad$ fugacity of compound $i$

$K_{\mathrm{H}} \quad$ Henry's law constant

$n_{i}^{\mathrm{P}} \quad$ molar quantity of species $i$ in phase $\mathrm{P}$

$p \quad$ pressure

$R \quad$ universal gas constant

$T \quad$ temperature

$V \quad$ volume

$x_{i} \quad$ mole fraction of $i$ in the liquid phase

$Z_{i} \quad$ compressibility factor for compound $i$

$\Delta_{\text {sol }} G \quad$ Gibbs energy of solvation

$\Delta_{\text {sol }} H$ enthalpy of solvation

$\Delta_{\text {sol }} S$ entropy of solvation

$\phi_{i} \quad$ fugacity coefficient of $i$

\begin{tabular}{ll}
\multicolumn{2}{l}{ Subscripts and superscripts } \\
1 & solvent property \\
2 & solute property \\
$\infty$ & at infinite dilution \\
$\circ$ & standard state \\
eq & at thermodynamic equilibrium \\
GB & gas bulb \\
ini & initial values \\
liq & liquid \\
sol & solvation property \\
tot & total
\end{tabular}

\section{References}

[1] S.N.V.K. Aki, B.R. Mellein, E.M. Saurer, J.F. Brennecke, J. Phys. Chem. B. 108 (2004) 20355-20365.

[2] A. Berger, R.F. de Souza, M.R. Delgado, J. Dupont, Tetrahedron: Assymetry 12 (2001) 1825-1828.

[3] J.L. Anthony, E.J. Maginn, J.F. Brennecke, J. Phys. Chem. B. 106 (2002) $7315-7320$.

[4] C. Cadena, J.L. Anthony, J.K. Shah, T.I. Morrow, J.F. Brennecke, E.J. Maginn, J. Am. Chem. Soc. 126 (2004) 5300-5308.

[5] R.E. Baltus, B.H. Culbertson, S. Dai, H. Luo, D.W. DePaoli, J. Phys. Chem. B. 108 (2004) 721-727.

[6] C.A. Ohlin, P.J. Dyson, G. Laurenczy, Chem. Commun. (2004) 1070-1071.

[7] A.P.S. Kamps, D. Tuma, J. Xin, G. Maurer, J. Chem. Eng. Data 48 (2003) 746-749.

[8] Z. Liu, W. Wu, B. Han, Z. Dong, G. Zhao, J. Wang, T. Jiang, G. Yang, Chem. Eur. J. 9 (2003) 3897-3903.

[9] P.J. Dyson, G. Laurenczy, C.A. Ohlin, J. Vallance, T. Welton, Chem. Commun. (2003) 2418-2419.

[10] Y.S. Kim, W.Y. Choi, J.H. Jang, K.-P. Yoo, C.S. Lee, Fluid Phase Equilib. 228-229 (2005) 439-445.

[11] J. Kumelan, A.P.S. Kamps, D. Tuma, G. Maurer, Fluid Phase Equilib. 228-229 (2005) 207-211.

[12] J.L. Anthony, J.L. Anderson, E.J. Maginn, J.F. Brennecke, J. Phys. Chem. B. 109 (2005) 6366-6374.

[13] K.R. Seddon, A. Stark, M.-J. Torres, Pure Appl. Chem. 72 (2000) 2275-2287.

[14] P. Husson-Borg, V. Majer, M.F. Costa Gomes, J. Chem. Eng. Data 48 (2003) 480-485.

[15] M.F. Costa Gomes, P. Husson, J. Jacquemin, V. Majer, Interactions of gases with ionic liquids: experimental approach, in: R.D. Rogers, K.R. Seddon (Eds.), ACS Symposium Series Ionic Liquids. Part III. Fundamentals, Progress, Challenges, and Opportunities, American Chemical Society Publications, Washington, DC, 2005, pp. 207-218 (Chapter 16).

[16] J. Jacquemin, M.F. Costa Gomes, P. Husson, V. Majer, J. Chem. Thermodyn. (in press).

[17] IUPAC Commission on Atomic Weights and Isotopic Abundances, Atomic weights of the elements 1985, Pure Appl. Chem. 58 (1986) 1677-1692.

[18] J.H. Dymond, E.B. Smith, The Virial Coefficients of Pure Gases and Mixtures, Clarendon Press, Oxford, 1980.

[19] J. Jacquemin, P. Husson, A.A.H. Padua, V. Majer, Green Chem. (in press).

[20] J. Kumelan, A.P.-S. Kamps, I. Urukova, G. Maurer, J. Chem. Thermodyn. 37 (2005) 595-602.

[21] J.H. Hildebrand, J.M. Prausnitz, R.L. Scott, Regular and Related Solutions, Van Nostrand Reinhold, New York, 1970, pp. 111-141.

[22] J. Deschamps, M.F. Costa Gomes, A.A.H. Padua, Chem. Phys. Chem. 5 (2004) 1049-1052.

[23] S.G. Kazarian, B.J. Briscoe, T. Welton, Chem. Commun. (2000) 2047-2048.

[24] D. Camper, P. Scovazzo, C. Koval, R. Noble, Ind. Eng. Chem. Res. 43 (2004) 3049-3054.

[25] S. Zhang, X. Yuan, Y. Chen, X. Zhang, J. Chem. Eng. Data 50 (2005) 1582-1585.

[26] M.B. Shiflett, A. Yokozeki, Ind. Eng. Chem. Res. 44 (2005) 4453-4464. 